\title{
PERLINDUNGAN HUKUM TERHADAP PASIEN BPJS KESEHATAN DALAM PROSEDUR PEMBEDAHAN YANG BIAYA PENGOBATANNYA MELEBIHI TARIF INA CBGS
}

\author{
Kelda Ayu Fitriani, Bambang Eko Turisno \\ Program Studi S2 Magister Kenotariatan, \\ Fakultas Hukum, Universitas Diponegoro
}

\begin{abstract}
There are still shortcomings in the implementation of BPJS Kesehatan in Indonesia. One of them is about the tariff system of INA CBGs. This system is a "package" payment system based on the illness of the patient. If patients are required to undergo surgical procedures that cost is not small. So how is the legal protection obtained by the patient if the cost incurred exceeds the established rates of INA CBGs. This study aims to determine and analyze the legal basis for determining patient rates on medical actions in hospitals by BPJS Kesehatan based on INA $C B G$ s and how about the legal protection of BPJS Kesehatan patients in surgical procedures whose medical expenses exceed the tariff of INA CBGs. Approach method used in this research is juridical empirical with descriptive research specification analysis. From the results of the study, regarding the cost of hospital treatment of patients surgical procedures that exceed the rate of INA CBGs, the excess costs will not be charged to patients BPJS Kesehatan but will still be borne by BPJS Health. This can happen because BPJS Kesehatan uses the principle of gotong royong by providing legal protection consistently based on the provisions of Article 4 of Law Number 8 Year 1999.
\end{abstract}

Keywords : BPJS Kesehatan, INA CBGs, Surgery, Legal Protection

\begin{abstract}
Abstrak
Dewasa ini masih terdapat kekurangan dalam pelaksanaan BPJS Kesehatan di Indonesia. Salah satunya mengenai sistem tarif INA CBGs. Sistem ini merupakan sistem pembayaran dengan sistem "paket", berdasarkan penyakit yang diderita pasien. Terlebih lagi jika pasien diharuskan menjalani prosedur pembedahan yang biayanya tidak sedikit. Sehingga bagaimana pasien dapat memperoleh perlindungan hukum apabila biaya yang dikeluarkan melebihi tarif INA CBGs yang telah ditetapkan. Penelitian ini bertujuan untuk mengetahui dasar hukum penentuan tarif pasien terhadap tindakan medis di Rumah sakit oleh BPJS Kesehatan berdasarkan INA CBGs serta bagaimana perlindungan hukum terhadap pasien BPJS Kesehatan dalam prosedur pembedahan yang biaya pengobatannya melebihi tarif INA CBGs. Metode pendekatan yang digunakan dalam penelitian ini adalah metode pendekatan yang bersifat yuridis empiris dengan spesifikasi penelitian deskriptif analisis. Dari hasil penelitian menunjukkan bahwa dalam hal biaya perawatan rumah sakit pasien prosedur pembedahan yang melebihi tarif INA CBGs, kelebihan biaya tersebut tidak akan dibebankan kepada pasien BPJS Kesehatan melainkan akan tetap ditanggung oleh BPJS Kesehatan. Hal ini dikarenakan BPJS Kesehatan menggunakan prinsip gotong royong. BPJS Kesehatan memberikan perlindungan hukum dengan berlandaskan Pasal 4 Undang-Undang Nomor 8 Tahun 1999 tentang Perlindungan Konsumen. Sehingga BPJS Kesehatan menanggung semua biaya pengobatan yang dibutuhkan masyarakat tanpa dipungut biaya lagi selain iuran per bulan
\end{abstract}

Kata kunci : BPJS Kesehatan, INA CBGs, Pembedahan, Perlindungan Hukum 


\section{A. Pendahuluan}

Sudah menjadi hakikatnya manusia mengalami keadaan yang tidak kekal yang merupakan sifat alamiah tersebut mengakibatkan adanya suatu keadaan yang tidak dapat diramalkan lebih dahulu secara tepat sehingga dengan demikian keadaan termaksud tidak akan pernah memberikan rasa pasti. Keadaan tidak pasti terhadap setiap kemungkinan yang dapat terjadi baik dalam bentuk atau peristiwa yang belum tertentu menimbulkan rasa tidak aman yang lazim disebut risiko ${ }^{1}$.

Dalam kehidupan manusia, sadar atau tidak pasti menghadapi risiko. Sebagaimana dikemukakan oleh Agus Prawoto, risiko dapat berasal dari berbagai hal yang tidak diharapkan, namun dari suatu kemungkinan (probality) ${ }^{2}$. Jadi risiko itu merupakan sesuatu yang tidak dapat dipisahkan dari kehidupan manusia. Di samping itu tidak ada seorangpun yang dapat bebas dari suatu risiko. Meskipun demikian, sudah barang tentu seseorang atau beberapa orang lebih terbuka atas kemungkinan terhadap satu atau beberapa jenis risiko dibandingkan dari satu atau beberapa orang lain.

Mamduh M. Hanafi mengemukakan²:

"Kematian itu sendiri merupakan hal yang pasti, tetapi timming (waktu) dari kematian adalah tidak pasti. Ketidakpastian tersebut yang menimbulkan risiko"

Salah satu hal yang menyebabkan timbulnya risiko dalam kehidupan manusia adalah penyakit yang menyebabkan seseorang menjadi tidak sehat. Manusia dalam memenuhi salah satu kebutuhan pokoknya, kebutuhan pokok kesehatan, akan melakaukan perilaku tertentu. Seseorang akan selalu berusaha untuk mendapatkan biaya pemeliharaan kesehatan. Kesehatan merupakan hal yang sangat penting yang dimiliki oleh manusia, oleh sebab itu banyak masyarakat yang merasa perlu untuk melindungi kesehatannya sendiri dari segala macam risiko yang akan timbul akibat dari risiko kesehatan. Manusia lebih memilih untuk melimpahkan risiko kesehatan ini kepada pihak-pihak lain di luar dirinya sendiri.

Kesehatan adalah hak dasar setiap orang, dan semua warga negara berhak mendapatkan pelayanan kesehatan. UUD 1945 mengamanatkan bahwa jaminan kesehatan bagi masyarakat, khususnya yang miskin dan tidak mampu, adalah tanggung jawab pemerintah pusat dan daerah.Pada UUD 1945 Perubahan, Pasal 34 ayat (2) menyebutkan bahwa negara

\footnotetext{
${ }^{1}$ Sri Redjeki Hartono, Hukum Asuransi Dan Perusahaan Asuransi (Jakarta: Sinar Grafika, 1992).

2 Agus Prawoto, Hukum Asuransi Dan Kesehatan Perusahaan Asuransi Berdasarkan Risk Base Capital (RBC), 2nd edn (Yogyakarta: BPFE, 1995).

${ }^{3}$ Mamduh M. Hanafi, Manajemen Risiko, 2nd edn (Yogyakarta: UPP STIM YKPN, 2009).
} 
mengembangkan Sistem Jaminan Sosial bagi seluruh rakyat Indonesia. Pemerintah menjalankan UUD 1945 tersebut dengan mengeluarkan Undang-Undang Nomor 40 Tahun 2004 tentang Sistem Jaminan Sosial Nasional (SJSN) untuk memberikan jaminan sosial menyeluruh bagi setiap orang dalam rangka memenuhi kebutuhan dasar hidup yang layak menuju terwujudnya masyarakat Indonesia yang sejahtera, adil, dan makmur. Dalam Undang-Undang Nomor 36 Tahun 2009 tentang Kesehatan juga ditegaskan bahwa setiap orang mempunyai hak yang sama dalam memperoleh akses atas sumber daya di bidang kesehatan dan memperoleh pelayanan kesehatan yang aman, bermutu, dan terjangkau.

Dengan adanya BPJS Kesehatan, menunjukkan bahwa tanggungjawab pemerintah terlihat dalam melindungi kesehatan warganya, seperti yang tercantum di dalam Undang-undang Dasar Negara Republik Indonesia tahun 1945 mengamanatkan bahwa setiap penduduk berhak atas jaminan sosial dan pelayanan kesehatan yang sama, seperti halnya tercermin dalam Pasal $28 \mathrm{H}$ dan Pasal 34 Undang-Undang Dasar Negara Republik Indonesia tahun 1945.

Setiap orang atau masyarakat mempunyai hak dalam bidang kesehatan seperti yang telah diatur dalam Undang-Undang Nomor 36 tahun 2009 tentang Kesehatan sebagai berikut:

1. Setiap orang berhak atas kesehatan.

2. Setiap orang mempunyai hak dalam memperoleh pelayanan kesehatan yang aman, bermutu dan terjangkau.

3. Setiap orang berhak untuk mendapatkan informasi dan edukasi tentang kesehatan yang seimbang dan bertanggung jawab.

4. Setiap orang berhak memperoleh informasi tentang data kesehatan dirinya termasuk tindakan dan pengobatan yang telah maupun yang akan diterimanya dari tenaga kesehatan.

Terlihat dari beberapa hak yang diterima oleh konsumen, sudah seharusnya konsumen mendapatkan perlindungan dari pelaku usaha yakni BPJS Kesehatan terutama dalam hal pembayaran biaya pengobatan yang diterima oleh konsumen harus jelas dan transparan.Konsumen disini pun mereka membayar sesuai dengan kesepakatan di awal berdasarkan kelasnya masing-masing. Jadi sudah menjadi hak bagi konsumen untuk mendapatkan jaminan kesehatan yang layak dan sesuai dengan apa yang telah disepakati antara pelaku usaha dan konsumen. Dalam Pasal 19 ayat (2) Undang-Undang Nomor 40 Tahun 2004 tentang Sistem Jaminan Sosial Nasional juga menyatakan bahwa:

"Jaminan kesehatan diselenggarakan dengan tujuan menjamin agar peserta memperoleh manfaat pemeliharaan kesehatan dan perlindungan dalam memenuhi kebutuhan dasar kesehatan." 
Jadi kesimpulannya adalah kesehatan masyarakat benar-benar dilindungi oleh pemerintah dengan cara membayarkan biaya kesehatan dengan uang anggaran dari pemerintah yang diberikan kepada masing-masing rumah sakit maupun puskesmas yang ditunjuk oleh pemerintah provinsi di daerah masing-masing. Kemudian dilanjutkan dengan adanya Pasal 20 ayat (1) Undang-Undang Nomor 40 Tahun 2004 tentang Sistem Jaminan Sosial Nasional yang berbunyi bahwa:

"Peserta jaminan kesehatan adalah setiap orang yang telah membayar iuran atau iurannya dibayar oleh pemerintah.”

Seperti yang masyarakat ketahui bahwa pada implementasinya masih terdapat kekurangan dalam pelaksanaan BPJS Kesehatan di Indonesia yang tidak sesuai dengan harapan masyarakat.Ada beberapa hal yang masih banyak masyarakat tidak mengetahui mengenai peraturan BPJS Kesehatan. Salah satunya adalah mengenai sistem tarif INA CBGs. Sistem tarif INA CBGs ini merupakan sistem pembayaran dengan sistem "paket", berdasarkan penyakit yang diderita pasien. Tidak banyak masyarakat mengetahui mengenai sistem tarif INA CBGs yang telah diatur dalam Peraturan Menteri Kesehatan Nomor 64 Tahun 2016 tentang Standar Tarif Pelayanan Kesehatan dalam Penyelenggaraan Program Jaminan Kesehatan. Sebenarnya penting bagi masyarakat untuk mengetahui bagaimana sistem tarif INA CBGs ini berlaku, agar kedepannya masyarakat yang merupakan konsumen ini tidak dirugikan oleh pihak-pihak yang tidak bertanggungjawab. Karena masyarakat sering dibuat bingung oleh penerapan tarif INA CBGs yang bahkan terkadang mereka sendiri tidak mengetahui apa arti dari tarif INA CBGs itu sendiri.

Adapun dalam Peraturan Menteri Kesehatan Nomor 64 Tahun 2016 tentang Standar Tarif Pelayanan Kesehatan dalam Penyelenggaraan Program Jaminan.

Kesehatan telah diatur mengenai tarif INA CBGs pada setiap penanganan atau pengobatan terhadap pasien BPJS Kesehatan. Salah satu contohnya adalah Pembedahaan bypass pembuluh koroner dengan kateterisasi jantung (berat) yang tarif INA CBGs nya Rp 118.389.600,- untuk kelas 3. Ada satu kasus dimana dalam tindakan pembedahan diatas, ternyata biaya yang dikeluarkan melebihi dari tarif INA CBGs. Tentu hal ini dapat membuat bingung masyarakat dalam membayar kelebihan dari tarif INA CBGs tersebut.Apalagi pasien BPJS Kesehatan yang berada pada kelas 3 merupakan masyarakat yang menengah ke bawah. Mereka tentu tidak dapat membayar kelebihan biaya tersebut. 
Peserta BPJS Kesehatan merupakan konsumen yang menikmati jasa pelayanan kesehatan yang diberikan oleh perusahaan BPJS Kesehatan. Sesuai dengan Pasal 2 Undang-undang Nomor 8 Tahun 1999 tentang Perlindungan Konsumen terdapat lima asas yang menjadi pijakan utama, salah satunya adalah asas keadilan, asas ini dimaksudkan agar partisipasi seluruh rakyat bisa terwujud secara maksimal dan memberikan kesempatan kepada konsumen dan pelaku usaha untuk memperoleh haknya dan melaksanakan kewajibannya secara adil. Serta asas keamanan dan keselamatan konsumen, asas ini dimaksudkan untuk memberikan jaminan atas keamanan dan keselamatan kepada konsumen dalam penggunanaan, pemakaian, dan pemanfaatan barang atau jasa yang dikonsumsi atau digunakan.

Di sisi lain, pasien BPJS Kesehatan yang merupakan konsumen tentunya sudah ada perjanjian atau kesepakatan di awal dengan BPJS Kesehatan. Sesuai dengan prosedur dari BPJS Kesehatan yang mengharuskan konsumen untuk membayar sejumlah uang tiap bulannya berdasarkan kelas masing-masing yang telah mereka ambil. Dengan teraturnya pembayaran iuran, konsumen sudah dipastikan terjamin atas kesehatannya oleh BPJS Kesehatan, termasuk pasien BPJS

Kesehatan yang harus menjalani prosedur pembedahan. Seperti contoh di atas prosedur pembedahan jantung yang membutuhkan biaya tidak sedikit. Adanya tarif INA CBGs ini membantu pihak rumah sakit untuk menentukan biaya yang harus dikeluarkan untuk pasien BPJS Kesehatan beradasarkan kelas masing-masing. Namun, bagaimana bila biaya prosedur pembedahan tersebut ternyata melebihi tarif INA CBGs yang telah ditentukan BPJS Kesehatan terhadap Rumah Sakit?

Dari apa yang dikemukakan di atas, dapat ditarik suatu kesimpulan bahwa sangat penting untuk dapat melindungi konsumen dari berbagai hal yang dapat merugikan mereka. Masyarakat yang merupakan konsumen perlu dilindungi, karena konsumen dianggap memiliki suatu "kedudukan" yang tidak seimbang dengan para pelaku usaha. Perlindungan konsumen yang dijamin oleh undang-undang ini adanya kepastian hukum terhadap segala perolehan kebutuhan konsumen. Kepastian hukum itu meliputi segala upaya berdasarkan hukum untuk mempertahankan atau membela hak-haknya apabila dirugikan oleh perilaku pelaku usaha yang bersangkutan ${ }^{4}$.

Berdasarkan latar belakang yang telah diuraikan sebelumnya, maka peneliti mengidentifikasi permasalahan dalam penulisan ini adalah bagaimana dasar hukum penentuan tarif pasien terhadap tindakan medis di Rumah Sakit oleh BPJS Kesehatan berdasarkan INA

\footnotetext{
${ }^{4}$ Adrian Sutedi, Tanggung Jawab Produk Dalam Hukum Perlindungan Konsumen (Bogor: Ghalia Indonesia, 2008).
} 
CBGs dan bagaimana perlindungan hukum terhadap pasien BPJS Kesehatan dalam prosedur pembedahan yang biaya pengobatannya melebihi tarif INA CBGs

\section{B. Metode Penelitian}

Metode pendekatan yang digunakan dalam penelitian ini adalah metode pendekatan yang bersifat yuridis empiris dengan spesifikasi penelitian deskriptif analisis. Data yang dijadikan pedoman dalam metode pengumpulan data yaitu data primer dan data sekunder. Penelitian ini dianalisis dengan metode analisis kualitatif.

\section{Hasil dan Pembahasan}

\section{Dasar Hukum Penentuan Tarif Pasien Terhadap Tindakan Medis di Rumah Sakit oleh BPJS Kesehatan berdasarkan INA CBGs}

Tarif yang telah ditentukan oleh Pemerintah melalui Menteri Kesehatan ini dengan menggunakan sistem tarif INA CBGs, ditetapkan dalam Peraturan Menteri Kesehatan Nomor 59 Tahun 2014 tentang Standar Tarif Pelayanan Kesehatan dalam Penyelenggaraan Jaminan Kesehatan, sehingga ini merupakan dasar hukum penetapan tarif INA CBGs. Dengan adanya perubahan-perubahan yang dilakukan Menteri Kesehatan, tarif INA CBGs telah ditetapkan dalam Peraturan Menteri Kesehatan Nomor 64 Tahun 2016 tentang Standar Tarif Pelayanan Kesehatan dalam Penyelenggaraan Jaminan Kesehatan.

Manfaat yang dapat diperoleh dari penerapan kebijakan program casemix INA CBGs secara umum adalah secara medis dan ekonomi. Dari segi medis, para klinisi dapat mengembangkan perawatan pasien secara komprehensif, tetapi langsung kepada penanganan penyakit yang diderita oleh pasien. Secara ekonomi, dalam hal ini keuangan (costing) kita jadi lebih efisien dan efektif dalam penganggaran biaya kesehatan. Sarana pelayanan kesehatan akan menghitung dengan cermat dan teliti dalam penganggarannya. Dengan menggunakan sistem itu, maka perhitungan tarif pelayanan lebih objektif berdasarkan pada biaya sebenarnya.

Adapun manfaat yang diperoleh bagi pasien, adanya kepastian dalam pelayanan dengan prioritas pengobatan berdasarkan derajat keparahan. Dengan adanya batasan pada lama rawat (length of stay) pasien mendapatkan perhatian lebih dalam tindakan medis dari para petugas rumah sakit, karena berapapun lama rawat yang dilakukan biayanya sudah ditentukan. Pasien menerima kualitas pelayanan kesehatan yang lebih baik. Mengurangi pemeriksaan dan penggunaan alat medis yang berlebihan oleh tenaga medis sehingga mengurangi resiko yang dihadapi pasien. 
Sebelum INA CBGs diterapkan di Indonesia, INADRG terlebih dahulu digunakan mulai tahun 2009. INADRG kepanjangan dari Indonesian Diagnostic Related Group, yang merupakan sistem klasifikasi kombinasi dari beberapa jenis penyakit diagnosa dan prosedur tindakan pelayanan untuk penentuan tarif klaim Jamkesmas yang digunakan di rumah sakit. DRG (Diagnostic Related Group) adalah suatu sistem pemberian jasa pelayanan kesehatan kepada Penyedia Pelayanan Kesehatan (PPK) yang ditetapkan berdasarkan pengelompokan diagnosa penyakit 5 .

Sistem grouper INA CBGs dibuat dari sistem casemix UNU-IIGH (The United Nations University-International Institute for Global Health). Proyek UNU INA CBGs ini didanai oleh Australian Agency for International Development (AusAID). Manual untuk INA CBGs resmi diserahkan pada Kementerian Kesehatan Indonesia pada Januari 2013. Aplikasi INA CBGs berbasis web based untuk interface entri datanya, berbeda dengan INADRG yang berbasis aplikasi desktop.

Dalam pelaksanaan Casemix INA CBGs, peran koding sangat menentukan, dimana logic software yang digunakan untuk menentukan tarif adalah dengan pedoman ICD 10 CM untuk menentukan diagnosis dan ICD 9 CM untuk tindakan prosedural. Besar kecilnya tarif yang muncul dalam Software INA CBGs ditentukan oleh diagnosis dan prosedur. Kesalahan penulisan diagnosis akan mempengaruhi tarif. Tarif bisa menjadi lebih besar atau lebih kecil. Diagnosis dalam kaidah CBGs, harus ditentukan diagnosa utama dan diagnosa penyerta (diagnosa sekunder), diagnosa penyerta terdiri dari diagnosa komplikasi dan komorbiditas.

Diagnosa penyerta juga dapat mempengaruhi besar kecilnya tarif, karena akan mempengaruhi severity level (tingkat keparahan) yang diderita oleh pasien. Logikanya pasien yang dirawat terjadi komplikasi, maka akan mempengaruhi lama perawatan di rumah sakit. Jika lama perawatan bertambah lama dibanding tidak terjadi komplikasi, maka akan menambah jumlah pembiyaan dalam perawatan. Dalam Logic software INA CBGs penambahan tarif dari paket yang sebenarnya, jika terjadi tingkat keparahan 2 dan tingkat 3. Jika dalam akhir masa perawatan terjadi lebih dari satu diagnosis, koder harus bisa menentukan mana yang menjadi diagnosa utama maupun sekunder, yaitu :

a. Diagnosa Utama (principal diagnosis)

adalah diagnosa akhir/final yang dipilih dokter pada hari terakhir perawatan dengan kriteria paling banyak menggunakan sumber daya atau yang menyebabkan hari perawatan paling lama. Diagnosa utama selalu ditetapkan pada akhir perawatan seorang pasien

\footnotetext{
${ }^{5}$ Iryad Ahari, 2017, Wawancara, Kepala Manajemen Pelayanan Rujukan, Semarang
} 
(established at the end of the episode of health care). Jika lebih dari satu diagnosis maka dipilih satu diagnosis yang paling banyak menggunakan resources (SDM, bahan habis pakai, peralatan medik, tes pemeriksaan dan lain-lain).

b. Diagnosa sekunder adalah diagnosa selain diagnosa utama yang muncul atau sudah ada sebelum dan selama dirawat di rumah sakit, diagnosa sekunder terdiri dari diagnosa penyerta (comorbidity) dan diagnosa penyulit (complication). Diagnosis sekunder akan mempengaruhi besar kecilnya tarif INA CBGs, dapat menaikkan level-severity (tingkat keparahan) yang diderita pasien. Namun tidak semua diagnosa sekunder akan menaikkan tarif INA CBGs hanya diagnosa tertentu saja. Tarif INA CBGs yang telah ada akan direview kembali setelah dua tahun waktu berjalan, dalam waktu dua tahun tarif akan dievaluasi kembali.

c. Diagnosa Penyerta (comordibity)

adalah diagnosa selain diagnosa utama yang sudah ada bersama pasien sebelum masuk dan dirawat di rumah sakit.

d. Diagnosa Penyulit (complication)

adalah diagnosa selain diagnosa utama yang muncul ketika dalam perawatan pasien di rumah sakit.

Dalam Tindakan atau prosedur juga ada prosedur utama dan prosedur sekunder, yaitu :

a. Prosedur Utama (Principal Procedure) adalah prosedur tindakan yang paling banyak menghabiskan sumber daya atau menyebabkan hari rawatan paling lama dan biasanya berhubungan erat dengan diagnosa utama.

b. Prosedur Sekunder adalah seluruh signifikan prosedur tindakan yang dijalankan pada pasien rawat inap atau rawat jalan, membutuhkan peralatan special atau dikerjakan oleh staf terlatih dan berpengalaman.

Ini merupakan contoh perhitungan klaim rawat inap JKN BPJS Kesehatan, Pasien dirawat di rumah sakit tipe C, Regional 1, dengan kelas perawatan kelas 3.

a. Diagnosis utama thypoid.

Tarif klaim 2.774.500A-4-14-I penyakit infeksi bakteri dan parasit lain-lain ringan.

b. Diagnosis utama thypoid, diagnosis sekunder anemia.

Tarif klaim 3.568.700A-4-14-II penyakit infeksi bakteri dan parasit lain-lain sedang.

c. Diagnosis utama thypoid, diagnosis sekunder DHF dan anemia.

Tarif klaim 4.088.900A-4-14-III penyakit infeksi bakteri dan parasit lain-lain berat. 
Perhitungan diatas merupakan tarif klaim untuk diagnosis utama thypoid rumah sakit tipe C di regional 1 dengan kelas perawatan kelas 3, jika diagnosis utama penyakit lain, rumah sakit tipe lain, atau kelas perawatan lain maka akan berbeda lagi tarif klaimnya.

Dalam Casemix INA CBGs kode CBGs dibagi dalam 4-sub groups. Sub-groups ke 1 menunjukan CMGs (Case Main Group's) yang ditandai dengan huruf alpabetik (A-Z), dalam hal ini huruf "A" menjadi sub groups pertama sebagai CMGs (Case Main Groups) dari Infectious and Parasitic Diseases Groups dan diagnosis thypoid termasuk di dalamnya, sedangkan huruf "A" mengacu pada chapter dalam ICD-10, angka pertama dalam kode ICD-10, yaitu A14. Subgroups ke 2 menunjukan tipe kasus, yang ditandai dengan angka (1-9), angka "4" dalam tipe kasus disini adalah tipe "Rawat Inap bukan Prosedur”. Sub-groups ke 3 menunjukan spesifikasi CBGs yang ditandai dengan angka (1-32), dalam hasil penelitian ini, diagnosis thypoid ditandai dengan angka 14 untuk spesifikasi CBGs nya. Sub-groups ke 4 menunjukan severity Level yang ditandai dengan angka romawi (I-III). Severity Level menunjukkan tingkat keparahan penyakit pasien.

Deskripsi dari A-4-14-I, II dan III berturut-turut adalah thypoid ringan, thypoid sedang dan thypoid berat. Terjadinya severity level dipengaruhi oleh beberapa faktor, antara lain adanya diagnosis sekunder maupun tindakan/prosedur dan juga umur pasien. Severity level juga berpengaruh terhadap besarnya tarif yang diterima oleh rumah sakit.

Masyarakat dapat melihat secara langsung tarif INA CBGs yang telah ditentukan dengan melihat pada Peraturan Menteri Kesehatan Nomor 64 Tahun 2016 tentang Standar Tarif Pelayanan Kesehatan dalam Penyelenggaraan Jaminan Kesehatan dan sudah berlaku sejak tanggal 26 Oktober 2016. Di dalamnya sudah terdapat semua nominal biaya-biaya yang telah ditetapkan dalam INA CBGs. Dalam menerapkan tarif INA CBGs ini, BPJS Kesehatan menggunakan prinsip gotong-royong. Prinsip gotong royong disini mempunyai arti yaitusupaya yang tidak sehat dapat dibantu yang sehat, yang kaya membantu yang miskin, dan yang muda ikut membantu yang tua, serta tidak ada pengembalian seperti layaknya yang diberlakukan asuransi swasta. Sehingga BPJS Kesehatan dapat memberikan perlindungan dengan menanggung semua biaya pengobatan yang dibutuhkan masyarakat tanpa dipungut biaya lagi selain iuran per bulan.

\section{Perlindungan Hukum Terhadap Pasien BPJS Kesehatan dalam Prosedur Pembedahan yang Biaya Pengobatannya Melebihi Tarif INA CBGs}


Sebenarnya tidak ada limit plafon untuk penggunaan BPJS Kesehatan untuk berobat di rumah sakit ${ }^{6}$. Biaya berobat dengan BPJS Kesehatan diatur dalam Peraturan Menteri Kesehatan Nomor 59 Tahun 2014 tentang Standar Tarif Jaminan Kesehatan Nasional atau sistem tarif INA CBGs. Tarif INA CBGs dibayarkan per episode pelayanan kesehatan, yaitu suatu rangkaian perawatan pasien hingga selesai. Dengan pola INA CBGs, paket pembayaran sudah termasuk :

a. Konsultasi dokter

b. Pemeriksaan penunjang, seperti laboratorium, radiologi (rontgen), dll

c. Obat Formularium Nasional (Fornas) maupun obat bukan Fornas

d. Bahan dan alat medis habis pakai

e. Akomodasi atau kamar perawatan

f. Biaya lainnya yang berhubungan dengan pelayanan kesehatan pasien

Komponen biaya yang sudah termasuk ke dalam paket INA CBGs, tidak dibebankan kepada pasien.

Pembedahan tubuh sengaja dibuat luka sehingga terjadi stres yang menyebabkan perubahan metabolik akibat reaksi endokrin yang kompleks.

Akibat dari luka terjadi proses penyebuhan luka yang merupakan proses kompleks dan banyak yang terkait. Kebutuhan kalori, protein, lemak dan elektrolit sangat diperlukan untuk kebugaran fisik dan penyembuhan luka pasca bedah.

Untuk kasus pembedahaan bypass pembuluh koroner pada jantung, dapat dijelaskan secara lebih rinci mengenai perawatan apa saja yang didapat selama menjalani masa pengobatan dari tahap pemeriksaan awal hingga pemulihan. Rincian ini sama untuk semua kelas, hanya bedanya pada ruang rawat inapnya saja. Adapun beberapa tahapan untuk mendapatkan pelayanan kesehatan BPJS Kesehatan dari tahap pemeriksaan awal hingga recovery, yaitu :

a. Tahap Pra Pembedahan

1) Pasien harus memenuhi persyaratan, yaitu :
a) Fotokopi Kartu BPJS Kesehatan
b) Fotokopi KTP atau tanda pengenal lainnya
c) Kartu berobat (jika belum mempunyai, bisa didapat pada faskes I)
d) Tidak menunggak dalam pembayaran iuran

2) Semua persyaratan itu diberikan kepada Faskes I (Klinik atau Puskesmas) untuk melakukan pemeriksaan awal dan menentukan harus dirujuk atau tidak ke Faskes II

\footnotetext{
${ }^{6}$ Iryad Ahari, 2017, Wawancara, Kepala Manajemen Pelayanan Rujukan, Semarang
} 
(Rumah Sakit), apabila hasil dari pemeriksaan diharuskan untuk dirujuk ke Faskes II maka dokter akan memberikan surat rujukan kepada pasien yang bersangkutan.

3) Surat rujukan ini akan ditujukan kepada Poliklinik Spesial Jantung dan Pembuluh Darah yang ada di Rumah Sakit Rujukan. Saat ke Poliklinik Spesial Jantung dan Pembuluh Darah, pasien harus membawa persyaratan dalam bentuk asli, yaitu : Kartu BPJS Kesehatan, KTP/tanda pengenal, Kartu Berobat, Surat Rujukan dari Faskes I untuk ditunjukkan kepada dokter spesialis jantung

4) Dokter spesialis jantung akan mengharuskan pasien untuk melakukan EKG (elektrokardiogram) terlebih dahulu dan hasilnya langsung diperiksa oleh dokter spesialis jantung.

5) Hasil dari EKG ini akan menentukan tingkatan keparahan penyakit yang diderita pasien, jika diharuskan untuk melakukan operasi bypass jantung maka pasien akan dirujuk ke poli gigi. Apabila Faskes II tidak mempunyai fasilitas kesehatan yang dibutuhkan pasien, dokter dari poli jantung akan memberikan rujukan ke Faskes III (Rumah Sakit Umum Pusat)

6) Untuk ke Faskes III, pasien harus menyiapkan persyaratan, seperti : fotokopi Kartu BPJS Kesehatan, fotokopi KTP/tanda pengenal, Surat Rujukan Rumah Sakit dari Faskes II, Surat Rujukan Dokter dari Faskes II. Setelah persyaratan semua sudah dipenuhi, pasien dapat langsung menuju ke poli jantung di Faskes III untuk mendapatkan rujukan intern ke poli gigi untuk langsung mendapatkan penanganan dari dokter gigi. Jika ada gigi yang berlubang, rusak, gigi palsu diharuskan untuk dicabut terlebih dahulu sebelum melakukan operasi bypass jantung

7) Dari poli gigi, pasien kembali ke poli jantung pada Faskes III untuk mendapatkan surat pengantar ke laboratorium untuk melakukan pemeriksaan laboratorium, seperti : tes darah lengkap, tes urine, usg jantung, rontgen, dan katerisasi

8) Setelah melakukan pemeriksaan laboratorium, pasien akan mendapatkan rujukan dokter untuk ke dokter spesialis bedah mulut dan dokter spesialis THT dengan membawa persyaratan yang sama saat dibawa ke poli gigi

b. Tahap Pembedahan

1) Setelah semua hasil pemeriksaan keluar, diantaranya :Tes darah lengkap, Tes urine, USG jantung, Rontgen, Katerisasi, THT, Gigi. Hasil pemeriksaan diserahkan kepada dokter bedah pada pertemuan terakhir sebelum pelaksanaan operasi yang sebelumnya sudah mendapatkan surat pengantar dari dokter jantung. 
2) Setelah operasi dilaksanakan, pasien akan dipindahkan ke ruang ICCU hingga keadaan pasien stabil.

c. Tahap Pasca Operasi

1) Apabila sudah stabil, maka pasien dapat dipindah ke ruang Intermediate untuk dilakukan recovery.

2) Recovery biasanya dilakukan selama 2-3 hari, setelah itu akan masuk ke ruang perawatan biasa.

Tidak ada perbedaan antara kelas 1, kelas 2, kelas 3 ketika pasien melakukan rawat jalan, namun perbedaanya adalah ketika pasien di rawat inap, maka pelayanan perawatan akan disesuaikan dengan kelas BPJS yang diambil oleh pasien yang bersangkutan.Perbedaan fasilitas fasilitas kamar perawatan ketika pasien harus di rawat inap.

Rincian biaya yang dihabiskan untuk operasi bypass jantung ringan kelas 3 di rumah sakit yang mendapatkan hak sesuai dengan kelasnya dan tarif INA CBGs yang ditanggung oleh BPJS Kesehatan.

Tabel 1. Rincian Biaya Operasi Bypass Jantung Kelas 3

\begin{tabular}{|l|l|l|}
\hline \multicolumn{1}{|c|}{ Jenis Pelayanan } & $\begin{array}{c}\text { Tarif } \\
\text { Rumah } \\
\text { Sakit* }\end{array}$ & $\begin{array}{c}\text { Tarif } \\
\text { INA } \\
\text { CBGs* }\end{array}$ \\
\hline Ruang Rawat Melati Kelas 3 selama 4 Hari & 1.000 & 1.000 \\
\hline Ruang Intermediate selama 2 hari & 660 & 330 \\
\hline Obat/Alkes Instalasi Farmasi & 580 & 400 \\
\hline Jasa Visit Dokter sebanyak 4 kali & 600 & 600 \\
\hline Tindakan Perawat Melati sebanyak 4 kali & 88 & 88 \\
\hline Tindakan Perawat Intermediate sebanyak 2 kali & 200 & 200 \\
\hline Tindakan Kamar Operasi & 80.453 & 78.584 \\
\hline Pemeriksaan Instalasi Laboratorium & 2.180 & 2.180 \\
\hline $\begin{array}{l}\text {-Test Darah Lengkap } \\
\text {-Test Urine } \\
\text {-USG Jantung } \\
\text {-Rontgen } \\
\text {-Katerisasi }\end{array}$ & & \\
\hline Pemeriksaan THT & 230 & 130 \\
\hline Pemeriksaan Gigi & 375 & 375 \\
\hline Alat Kesehatan & & 368 \\
\hline Obat Ruangan & & \\
\hline
\end{tabular}




\begin{tabular}{|l|l|l|}
\hline Fasilitas Lain-Lain & 56 & 56 \\
\hline Total Transaksi & 86.963 & 84.384 \\
\hline Biaya Administrasi & 274 & 180 \\
\hline Total Biaya & 87.237 & 84.564 \\
\hline Selisih Biaya & \multicolumn{2}{|c|}{2.673} \\
\hline
\end{tabular}

*) dalam ribuan rupiah

Dari rincian biaya perawatan di atas, tentu dapat dilihat bahwa biaya yang dikeluarkan lebih dari tarif INA CBGs. Ada selisih angka antara tarif INA CBGs dengan biaya yang dikeluarkan yaitu sebesar 2.673.000. Kelebihan biaya tersebut tidak akan dibebankan kepada pasien BPJS Kesehatan melainkan akan tetap ditanggung oleh BPJS Kesehatan. Pasien tidak akan diberikan tagihan atas biaya yang melebihi tarif INA CBGs, keseluruhan biaya perawatan sudah otomatis ditanggung oleh BPJS Kesehatan. Sehingga berapapun biaya pengobatannya dapat ditanggung oleh BPJS Kesehatan sesuai tarif INA CBGs, pasien tidak boleh ditarik biaya tambahan jika sudah sesuai prosedur dan sesuai hak kelas. Walaupun pasien membutuhkan operasi berbiaya tinggi atau cuci darah seumur hidup, biayanya dapat ditanggung oleh BPJS Kesehatan $^{7}$.

BPJS Kesehatan yang merupakan lembaga jaminan sosial dengan konsep asuransi sosial ini, memberikan perlindungan kepada setiap peserta yang terdaftar dalam BPJS Kesehatan tak terkecuali terhadap peserta yang mengharuskan melakukan prosedur pembedahan. Sehingga penyelesaian mengenai prosedur pembedahan yang melebihi tarif INA CBGs dapat dijabarkan seperti ini, ada sekelompok kasus atau diagnosis (maka disebut Grup) yang karena karakteristik dan biayanya dianggap satu kelompok, maka mendapatkan tarif yang sama. Dapat diambil sample ada 10 (sepuluh) diagnosis dalam satu grup, tarifnya sama. Pada kasus pertama misalnya ternyata tarif INA CBGs nya lebih rendah daripada tarif yang telah ditetapkan Rumah Sakit, sehingga ada defisit dalam kasus ini. Dalam kasus kedua, tarifnya sudah lebih mendekati tarif INA CBGs tetapi masih di bawah tarif yg ditetapkan Rumah Sakit, masih ada defisit walaupun lebih kecil daripada kasus pertama. Di kasus ketiga, keempat, kelima dan keenam, tarifnya sama dengan tarif INA CBGs walaupun ada yang lebih sedikit dari tarif INA CBGs dan ada yang sedikit dibawah tarif INA CBGs, hal ini dapat dikatakan impas. Pada empat kasus terakhir yaitu ketujuh, kedelapan, kesembilan dan kesepuluh, tarifnya melebihi tarif INA CBGs terlalu banyak, sehingga ada surplus dalam keempat kasus ini ${ }^{8}$.

\footnotetext{
${ }^{7}$ Iryad Ahari, 2017, Wawancara, Kepala Manajemen Pelayanan Rujukan, Semarang

${ }^{8}$ Iryad Ahari, 2017, Wawancara, Kepala Manajemen Pelayanan Rujukan, Semarang
} 
Jadi dari kesepuluh kasus di atas, memang tidak bisa diukur kasus per kasus. Secara kumulatif dalam sebulan misalnya, maka akan bisa dihitung berapa saldo kumulatifnya dari keseluruhan kasus yang telah dijabarkan di atas. Dari sana dapat terlihat bagaimana hasil akhirnya. Terkadang banyak masyarakat yang beranggapan bahwa tarif INA CBGs yang telah ditentukan tidak akan mampu mencukupi biaya pembedahan, apalagi dalam pembedahan jantung yang biayanya pasti tinggi. BPJS Kesehatan menganggap cara berpikir masyarakat terhadap tarif INA CBGs ini kurang tepat, karena seperti yang sudah dijelaskan di atas bahwa tidak semua pembedahan itu melebihi tarif INA CBGs ${ }^{9}$. Sehingga berapapun biaya yang dikeluarkan untuk pelayanan kesehatan, semua tetap ditanggung oleh BPJS Kesehatan sesuai dengan UndangUndang Nomor 24 Tahun 2011 tentang Badan Penyelenggara Jaminan Sosial Pasal 13 huruf d "Memberikan manfaat kepada seluruh peserta sesuai dengan Undang-Undang tentang Sistem Jaminan Sosial Nasional”.

\section{Simpulan}

Tarif INA CBGs merupakan tarif yang telah ditentukan oleh Pemerintah melalui Menteri Kesehatan. Manfaat yang dapat diperoleh dari penerapan kebijakan tarif INA CBGs secara umum adalah secara medis dan ekonomi. Dari segi medis, para klinisi dapat mengembangkan perawatan pasien secara komprehensif, tetapi langsung kepada penanganan penyakit yang diderita oleh pasien. Secara ekonomi, dalam hal ini keuangan (costing) kita jadi lebih efisien dan efektif dalam penganggaran biaya kesehatan. Sarana pelayanan kesehatan akanmenghitung dengan cermat dan teliti dalam penganggarannya. Dengan menggunakan sistem itu, maka perhitungan tarif pelayanan lebih objektif berdasarkan pada biaya sebenarnya. Melalui INA CBGs diharapkan dapat meningkatkan mutu dan efisiensi rumah sakit. Bagi pasien atau peserta BPJS Kesehatan dapat memberikan kepastian dalam pelayanan dengan prioritas pengobatan berdasarkan derajat keparahan. Dengan adanya batasan pada lama rawat (length of stay) pasien mendapatkan perhatian lebih dalam tindakan medis dari para petugas rumah sakit, karena berapapun lama rawat yang dilakukan biayanya sudah ditentukan. Pasien menerima kualitas pelayanan kesehatan yang lebihbaik. Mengurangi pemeriksaan dan penggunaan alat medis yang berlebihan oleh tenaga medis sehingga mengurangi resiko yang dihadapi pasien. Di dalamnya sudah terdapat semua nominal biaya-biaya yang telah ditetapkan dalam INA CBGs. Dalam menerapkan tarif INA CBGs ini, BPJS Kesehatan menggunakan prinsip gotong-royong. Prinsip gotong-royong disini mempunyai arti yaitusupaya yang tidak sehat dapat dibantu yang sehat,

\footnotetext{
${ }^{9}$ Iryad Ahari, 2017, Wawancara, Kepala Manajemen Pelayanan Rujukan, Semarang
} 
yang kaya membantu yang miskin, dan yang muda ikut membantu yang tua, serta tidak ada pengembalian seperti layaknya yang diberlakukan asuransi swasta.

Kelebihan biaya dalam prosedur pembedahan tidak akan dibebankan kepada pasien BPJS Kesehatan melainkan akan tetap ditanggung oleh BPJS Kesehatan. Pasien tidak akan diberikan tagihan atas biaya yang melebihi tarif INA CBGs, keseluruhan biaya perawatan sudah otomatis ditanggung oleh BPJS Kesehatan. Sehingga berapapun biaya pengobatannya dapat ditanggung oleh BPJS Kesehatan sesuai tarif INA CBGs, pasien tidak boleh ditarik biaya tambahan jika sudah sesuai prosedur dan sesuai hak kelas. Peserta BPJS Kesehatan selaku konsumen jasa pelayanan kesehatan dalam memperoleh pelayanan kesehatan, memiliki hak dan kewajiban. Sebelum mendapatkan pelayanan kesehatan dari BPJS Kesehatan, peserta diharuskan mengisi formulir 2A. Namun, di dalam formulir perjanjian yang dikeluarkan oleh BPJS Kesehatan hanya terdapat kolom persetujuan yang berisikan kewajiban konsumen (peserta) dan belum tercantum juga kewajiban yang harus dipenuhi BPJS Kesehatan. BPJS Kesehatan memang tidak secara khusus menjelaskan mengenai perlindungan yang diterima peserta prosedur pembedahan yang pengobatannya melebihi tarif INA CBGs, tetapi karena BPJS Kesehatan menggunakan konsep asuransi sosial yang berarti tidak membedakan peserta satu dengan lainnya maka perlindungan hukum yang diterima setiap peserta sama. Walaupun kewajiban BPJS Kesehatan tidak tertulis di dalam perjanjian, BPJS Kesehatan tetap menanggung semua pelayanan kesehatan termasuk prosedur pembedahan yang biayanya tentu tidak murah. Sehingga BPJS Kesehatan dapat memberikan perlindungan dengan menanggung semua biaya pengobatan yang dibutuhkan masyarakat tanpa dipungut biaya lagi selain iuran per bulan.

\section{DAFTAR PUSTAKA}

Hanafi, Mamduh M.. (2009). Manajemen Risiko, 2nd edn. Yogyakarta: UPP STIM YKPN.

Hartono, Sri Redjeki. (1992). Hukum Asuransi Dan Perusahaan Asuransi. Jakarta: Sinar Grafika.

Prawoto, Agus. (1995). Hukum Asuransi Dan Kesehatan Perusahaan Asuransi Berdasarkan Risk Base Capital (RBC), 2nd edn. Yogyakarta: BPFE.

Sutedi, Adrian. (2008). Tanggung Jawab Produk Dalam Hukum Perlindungan Konsumen. Bogor: Ghalia Indonesia. 